\title{
La viuda pobre como arquetipo marginal Estudio bíblico-literario
}

\author{
CÉSAR CARBULLANCA NÚÑEZ* \\ Universidad Católica del Maule (Chile) \\ carbullanca@yahoo.com \\ MARÍA DE LOS ANDES VALENZUELA CORALES** \\ Universidad Católica del Maule (Chile) \\ marie.valenz.86@gmail.com
}

\begin{abstract}
Resumen
La literatura universal, se encuentra poblada de arquetípicos que comparten una condición de desamparo y marginalidad, siendo la literatura realista de la segunda mitad del siglo XIX la que constata y da cuenta de su condición. En un mismo sentido, también la Biblia presenta un sinnúmero de personajes similares, marcando un punto de inflexión al llamarlo bienaventurados. Así pues, el presente estudio bíblico-literario, se centra en el arquetipo de la "viuda pobre", sosteniendo dicha ficción literaria es una clave interpretativa de la realidad, a la luz de la teoría literaria de la Estética de la Recepción. El articulo estudia la "viuda pobre" como un imaginario cultural y estableciendo la recepción de dicho imaginario en los cuentos "El Chiflón del diablo" y "El pago" del escritor chileno Baldomero Lillo, demostrando cómo el dialogo entre cultura y Biblia representa un aporte a la comprensión de determinadas ficciones literarias como categorías antropológicas.
\end{abstract}

Palabras clave: Estética de la recepción, Wolfgang Iser, viuda pobre, siervo sufriente. Baldomero Lillo.

\section{Poor widow as an outcasted archetype. Biblical-literary analysis}

\begin{abstract}
Universal literature is crowded by archetypical characters who share abandonment and marginalization conditions, being second half $19^{\text {th }}$ century realistic literature that comfirms and exposes those conditions. In that sense, The Holy Bible presents a number of those characters. Besides, it highlights a turning point, hence, The Beatitudes point out: "Blessed are the poor in spirit, for theirs is the kingdom of heaven". Thus, the following biblical-literary study, centered in the "Poor widow" archetype, aims to the establishment of literary fiction as interpretative key of reality, under Wolfgang Iser Aesthetics Reception's theory as its metodology. The objective aims to postulate "Poor Widow" as a Cultural imaginary, and finally to establish the reception of that imaginary within the stories "El Chiflón del Diablo" (The devil's blast) and "El Pago" ("The Payment") by the chilean writer Baldomero Lillo, demonstrating that the dialog between culture and The Holy Bible represents a contribution to some literary fictions as anthropological categories.
\end{abstract}

Key words: Aesthetics reception, Wolfgang Iser, poor widow, suffering servant, Baldomero Lillo.

* Doctor en Teología, Pontifica Universidad Comillas (Madrid). Investigador Fondecyt 1120029 .

** Magister en Ciencias Religiosas y Filosóficas, mención teología, por la Universidad Católica del Maule, Licenciada en Ciencias Jurídicas por la Universidad de Talca. Profesora asociada de la UCM. 


\section{INTRODUCCIÓN}

$\mathrm{Al}$ alero de los estudios religiosos actuales, se ha puesto en evidencia la multiculturalidad patente en todo tipo de manifestaciones religiosas que se constituye en estructura que organiza y atraviesa los más complejos entramados de las sociedades humanas, transformándose en objeto de interés para las Ciencias de la Religión. En dicho contexto, el estudio de la ficción y la reiteración de estructuras míticas, constituye un terreno fértil a la hora de demostrar la intrínseca relación existente entre ficción y la diversidad cultural que subyace al surgimiento de las religiones y las aproximaciones entre éstas, a partir de figuras arquetípicas o paradigmáticas.

En este sentido, cabe observar en la literatura universal la existencia de determinadas figuras que comparten una idea arquetípica de desamparo o vulnerabilidad, tales como huérfanos, enfermos de gravedad, ancianos, prostitutas o viudas, quienes, a través de la literatura, se han trasformado en ideas universales más allá de nuestros límites o fronteras territoriales, representándose en las tradiciones de lugares completamente lejanos y culturas disimiles.

Pero ¿están estos personajes constituidos de una forma azarosa?; su existencia ¿posee algún sentido particular? Pues ciertamente, su presencia no parece ser ingenua y surgen así, un sinnúmero de preguntas en este sentido, tales como ¿realizan algún aporte todos estos personajes paradigmáticos?, de ser así, ¿cuál es ese aporte? y ¿cómo se realiza? A nivel social o cultural, resulta complejo estimar que su condición podría ser una contribución en algún sentido.

En el plano literario, la literatura realista constata su condición de marginados sociales, mas parece no ir más allá, limitándose pues, como realismo literario a mostrar en las obras una reproducción fiel y exacta de la realidad, no reflexionando suficientemente sobre cuál podría ser el sentido o valor de su desgracia. Es entonces, la literatura religiosa la que, en apariencia, expresa un punto de inflexión en cuanto que sujetos desgraciados son portadores de sentido y valor para la sociedad. Así pues, de acuerdo a lo precedentemente señalado, desde un punto de vista metodológico, el presente estudio bíblico-literario, pretende, por un lado, establecer la ficción literaria como clave interpretativa de la realidad, a la luz de la teoría literaria de la Estética de la Recepción en la vertiente de Wolfgang Iser, por el otro, realizar un análisis literario basado en un estudio sincrónico de mitemas. Lo anterior nos permitirá a continuación postular, de los personajes mencionados, a la viuda pobre como partícipe del paradigma cultural de sujetos marginados; paradigma presente con particular fuerza en el evangelio de Lucas, pues es el que posee el mayor número de pasajes en alusión a las viudas y además marca un punto de inflexión en cuanto a su 
condición, pues viene en establecer el sufrimiento o la abyección como lugares en donde el ser humano se encuentra en comunión con Dios, evidenciando una perspectiva soteriológica en su condición. Finalmente, se desarrollará la recepción del modelo propuesto, en la obra de Baldomero Lillo, con el objetivo de probar la hipótesis de investigación propuesta, a saber, la viuda pobre como paradigma marginal.

\section{LA ESTÉTICA DE LA RECEPCIÓN Y LA FICCIÓN LITERARIA DE LA VIUDA POBRE COMO CATEGORÍA ANTROPOLÓGICA}

Wolfgang Iser fue un crítico y teórico de la literatura, nacido en $\mathrm{Ma}$ rienberg, Alemania el 22 de julio de 1926 y fallecido el 24 de enero de 2007. Estudió literatura en las universidades de Leipzig, Tübingen y Heidelberg. Fue profesor en la Universidad Heidelberg y en 1952 pasó a trabajar a la Universidad de Glasgow. Allí comenzó a explorar la filosofía y literatura contemporáneas, lo que profundizó su interés en el intercambio intercultural.

Es considerado, junto con Hans Robert Jauss, la figura más representativa de la Escuela de Constanza o de la Estética de la Recepción (Sánchez, 2005: 51). De esta forma, si, por un lado, el análisis con el que Hans Robert Jauss define las líneas maestras de la historia de la literatura, se convierte en soporte de las ideas medulares de la Estética de la recepción, casi con carácter programático, Wolfgang Iser, en el seno mismo de la Universidad de Constanza, asume estos planteamientos, aunque enfocándolos desde una nueva perspectiva que plasma en su obra "Der Akt des Lesens. Theorie ästhetischer Wirkung", o "El Acto de Leer: Teoría de Efecto Estético", de 1976, síntesis de todo su pensamiento ${ }^{1}$.

En este sentido, y a diferencia de Jauss, que llega a la estética de la recepción desde la historia literaria, Wolfgang Iser lo hace desde la Narratología e influenciado por la corriente de la fenomenología (Gallardo, 2011); retomó para ello, los estudios fenomenológicos del filósofo polaco Roman Ingarden y aspectos de la propuesta original de Edmmund Husserl, desarrollando una teoría enmarcada por las investigaciones sobre la estética de la recepción que se llevaban a cabo de manera general, en la Escuela de Constanza, Alemania. De esta forma, en la línea de Ingarden, Wolfgang Iser analiza el texto en función de las relaciones que mantiene con el lector, asentada en la idea de que un texto literario puede desarrollar

\footnotetext{
1 En El acto de leer (1976) convergen ideas que desarrolló antes en artículos como " $L a$ estructura apelativa de los textos" (1968), El lector implícito (1972) y "El proceso de lectura: enfoque fenomenológico"(1972).
} 
su efecto cuando es leído; la suya es una perspectiva fenomenológica, no culturalista o historicista (Gómez, 2007).

Se trata, además, de una teoría del efecto estético, encaminada a explicar los efectos que el texto causa en el lector, no a dilucidar los elementos formales o significativos que intervienen en la constitución del texto como objeto (Gómez, 2007).

$\mathrm{Al}$ respecto, destaca Iser (1987:12):

El efecto estético, por tanto, debe ser analizado en el triple avance dialéctico del texto y el lector, así como de la interacción que acontece entre ellos. Se llama efecto estético porque -aunque causado por el texto- exige la actividad de representar y percibir del lector, a fin de conducirle a una diferenciación de actitudes.

Así pues, la teoría de Wolfgang Iser propone, a grandes rasgos, tomar en cuenta la importancia de la interacción entre el texto y el lector en la respuesta estética, no obstante considerar que el texto tiene una estructura objetiva, a pesar de que dicha estructura deba ser completada por el lector.

\subsection{La estructura del texto y el proceso de recepción}

Siguiendo el planteamiento del autor, es relevante, primero que todo, comprender la naturaleza o estructura del texto, para lo cual Iser (1987). parte de un presupuesto: que el sentido del texto no está en él como una cualidad suya, objetiva que habría que descubrir, sino que aparece cuando es leído. Es decir, surge en el proceso de recepción, en una interacción o cooperación entre el texto y el lector, pero que se da en tanto que el texto posee una determinada estructura que hace posible, requiere y motiva la intervención del lector y que gira en torno al concepto de "espacios vacíos o en blanco" (Sánchez, 2005: 51). El lector, en la experiencia ficcional de su lectura, puede decir lo que el texto no ha dicho, enmarcámdose por consiguiente en el ámbito del silencio. Así pues, los espacios vacíos cumplen la función de incitar al lector a llenarlos, estimulándolo a poner en acción su imaginación, llenándolos con su actividad imaginativa y determinando así lo indeterminado. Tal actividad recibe el nombre de "concretización" (Iser, 1987:149).

Así pues, Iser (1987) señala que la teoría fenomenológica del arte hace particular hincapié en la idea de que, a la hora de considerar una obra literaria, ha de tenerse en cuenta no el texto en sí, sino también, y en igual medida, los actos que lleva consigo enfrentarse a dicho texto. De esta forma, el autor, siguiendo a Ingarden, confronta la estructura del texto 
literario con los modos por los cuales éste puede ser konkretisiert (concretizado). El texto como tal ofrece diferentes "visiones esquematizadas" por medio de las cuales el tema de una obra puede salir a la luz, pero su verdadera manifestación es un acto de konkretisation (1987b: 149).

En este sentido, para Iser (1987) la obra es más que el texto, pues el texto solamente toma vida cuando es concretizado, siendo la convergencia entre texto y lector lo que dota a la obra literaria de existencia.

1.2. La Ficcionalización y dimensión antropológica de las ficciones literarias

Ahora bien, el proceso de recepción y la concretización de los espacios vacíos, nos lleva a pronunciarnos invariablemente sobre la naturaleza de las ficciones literarias, o los procesos ficcionales mismos que se dan en el mentado trabajo de concretización.

Esa es pues, la cuestión abordada por Wolfgang Iser en "Ficcionalización: la dimensión antropológica de las ficciones literarias". En este sentido, plantea Iser, que "la mayoría de las personas asocia el término ficción con el ámbito narrativo de la literatura" (Iser, 1990: 1). Sin embargo, su otra acepción alude directamente a una falsedad o una mentira. Betancourt (2005) estima que el equívoco tal vez proviene del hecho de que en las ficciones la realidad entraña una dualidad al sobrepasar los límites y exponer otros mundos posibles que, por su disposición contextual, los hacen parecer extraños pues incorporan una realidad identificable pero sometida a un cambio imprevisto que la diferencia del mundo real. La dualidad surge por el hecho de que, a pesar de que esa realidad se ha visto sobrepasada, ésta aún y continúa allí.

Para Iser (1990), la aparente asociación de terminologías no es del todo errada, pues ambos significados, tanto el de ficción como el de mentira o falsedad, comprenden procesos similares que el autor denomina "sobreposiciones". Así las cosas, en los llamados procesos de "ficcionalización", los mundos existentes se sobreponen y, a pesar de que son aun individualmente reconocibles, el autor estima que están puestos en un contexto que los desfamiliariza. Al respecto, señala:

Por lo tanto, la mentira y la literatura siempre contienen dos mundos: la mentira incorpora la verdad y el propósito por el cual la verdad tiene que esconderse; las ficciones literarias incorporan una realidad identificable, sujeta a una remodelización imprevisible. Así, cuando describimos la ficcionalización como un acto de sobreposición, debemos tener en mente que la 
realidad sobrepuesta no queda atrás: se mantiene presente, por lo que imbuye a la ficción con una dualidad explotable para diferentes propósitos (Iser, 1990: 1).

Así pues, de acuerdo a los postulados de Iser (1990), la reiteración de determinados procesos ficcionales, no es ingenua, si no que da cuenta de una realidad concreta, elevando la ficción literaria a categoría antropológica. El llamado proceso de ficcionalización propuesto por Iser (1990), radica específicamente en que, a pesar de que sabemos que nos adentra a mundos no reales, podría destacarse una necesidad intrínseca o inherente al ser humano de seguir ficcionalizando y ello es justamente lo que el autor analiza como la dimensión antropológica de las ficciones literarias, ya que parecen reflejar al hombre en situaciones propias de su entorno real, es decir, se parecen a la realidad que encubren o duplican (Iser, 1990).

\subsection{La ficción literaria de la viuda pobre}

Así las cosas, podemos evidenciar, ya en concreto, como en distintos periodos de la literatura universal, encontramos la figura de la mujer viuda, de acuerdo al concepto iseriano, sujeta a diversidad de procesos ficcionales. A modo de ejemplo, cabe señalar que el estatus sociopolítico de la mujer en la antigüedad, poseía un acentuado carácter marginal y de dependencia jerárquica respecto a la autoridad del varón. No parece extraño así, que ya desde la literatura antigua, se manifestara un pavor casi absoluto a la posibilidad de verse enfrentada la mujer al estado de viudez, por la consiguiente acentuación de su condición de marginada, como es posible constatar en diversos párrafos de "Áyax" de Sófocles o en las obras homéricas "La Iliada" y "La odiesa".

Así por ejemplo en "Áyax":

Cuando esto pidas, pide también mi muerte a la vez. Pues, ¿por qué tengo que vivir yo, si tú estás muerto? (...) Porque si tú mueres y, con ello me dejas abandonada, piensa que en ese día también yo, arrebatada a la fuerza por alguno de los argivos, juntamente con tu hijo, tendré el régimen de vida de una esclava (Sófocles, 2000: 9).

No obstante lo anterior, cabe resaltar, que en forma previa a todo atisbo de modernidad, se asocia al paradigma ficcional de la viuda pobre, la existencia de una cierta idea de expiación por medio de sus actos, presente en textos bíblicos y sagrados de otras culturas. La ofrenda de aquella mujer que nada tiene, reafirma la connotación paradigmática o arquetípica de la viuda pobre objeto de este estudio. El referido modelo ficcional de 
tipo paradojal, se encuentra presente por ejemplo en el texto budista datado en el siglo I o II d.C. y casi idénticamente emparentado con la historia de la ofrenda de la viuda de Marcos 12, 41-44 y Lucas 21, 1-4, que nos lleva a sospechar la dimensión antropológica presente en la ficción de la viuda pobre y la existencia de una intencionalidad de fondo en su constante reiteración, a la luz de los postulados de Iser.

Un extracto del citado relato budista, reza de la siguiente forma:

Está bien, ¡benditos sacerdotes! Pero pese a que otros dan preciosas cosas tales como las que las cavidades del óceano produce, yo como pobre mujer nada tengo que dar". Habiendo hablado así y buscado en ella en vano algo para dar, recogió algo que algún tiempo atrás había encontrado en un montón de estiercol; dos óbolos (óbolos de cobres), tomando estos inmediatamente se los ofreció como regalo al sacerdocio en caridad (Haas, 1922: 109).

En definitiva, la idea de la viudez y sus múltiples formas de representación son un tema constante y reiterativo al que con frecuencia se vuelve a recurrir al momento de ficcionalizar sobre la mujer. Pareciera ser que la viuda, por su condición particular, muestra justamente ese rostro más desventajoso de la condición femenina, en mucho de los casos de edad avanzada y no pocas veces, en una condición económica y social absolutamente desfavorecida, se ve ineludiblemente condenada a un destino de dependencia, que puede ser asumido en forma negativa, pero dentro del cual podemos encontrar una dimensión salvífica o expiatoria, presente ya en textos antiguos, como el relato budista mencionado.

\section{LA VIUDA POBRE COMO ARQUETIPO MARGINAL EN EL EVANGELIO DE LUCAS}

Así pues, la reiteración constante del referido motivo literario en la literatura universal, hace al menos evidenciar a priori un estatus preferente de la elaboración imaginaria en torno a la referida ficción.

Corolario de lo anterior, como ya se ha dejado entrever, también la literatura bíblica es prolífica en lo que a viudas se refiere, siendo Lucas el evangelista que repite este motivo un mayor número de veces, sumando a la tradición de Marcos, tres pasajes más sobre Jesús y mujeres viudas, de lo cual podemos sostener que la aparición de tantas viudas en dicho evangelio, no es ingenua. Lucas está inmerso en un proceso ficcional, la existencia de sujetos privados de derechos políticos y estatuto de persona, son objeto de un constante proceso de ficcionalización, deviene en categoría antropológica. 
Ahora bien, cabe preguntarse ¿por qué entonces, es Lucas el evangelista que más subraya la predilección de Jesús por los pobres y en el caso de análisis, la figura femenina de la viuda pobre? Pareciera ser que la respuesta es bastante compleja, y no cabe limitarnos a señalar una supuesta predilección lucana por tal grupo de marginados o excluidos. La viuda pobre lucana, participa de una ficción literaria e imaginario cultural más amplio, de tipo bíblico y cultural, que se caracteriza fundamentalmente por la presencia de un "esquema teológico paradojal" (Carbullanca, 2014: 146) en el cual los beneficiarios del eschaton son los pobres, los que sufren y los que lloran y por una trasmutación total de los valores: "los pobres se hacen ricos, los hambrientos se sacian, los tristes son consolados y lo último llega a ser los primeros" (Jeremías, 1974: 248).

En este sentido, el referido imaginario cultural, sienta a partir del postdestierro una creencia en el valor soteriológico de sujetos marginales, tal como se muestra en la historia del Siervo de Yahvéh, presente en el cuarto cántico del libro de Isaías, tal como hemos señalado en investigaciones anteriores:

Un modelo soteriológico de pensamiento, el cual constituye como sujetos políticos y éticos a personas o grupos que se les ha privado de dicho estatuto en la sociedad humana, por la violencia fratricida, por su condición heterodoxa, o marginal, por su condición de excluido moral o religioso (Carbullanca, 2014: 147).

Y afirmando el carácter bienaventurado de estos grupos e individuos, víctimas de la violencia e injusticia (Carbullanca, 2014: 135).

Ahora bien, retomando la temática referente a la ficcionalización, cabe precisar que el Siervo de Yahvéh que se muestra en los pasajes de Isaías y en $1 \mathrm{QHa}$, tiene un ministerio que es sufriente que aparece desarrollado con mayor fuerza en el cuarto cántico y cuya recepción estética se encuentra presente en el evangelio de Lucas, quien ficcionaliza por ejemplo, los rasgos proféticos de Jeremías como profeta descrito en Is 61,1 en el pasaje de Lc 4,18, mismo texto que se repite en Lc 7,27, dando evidencia de la importancia de este imaginario.

2.1. Análisis del texto de Lucas 7:11-17 "Jesús resucita al hijo de la viuda de Naín"

El estudio de la recepción del texto que sigue, se realizará en base al análisis de los mitemas presentes en el mismo y su intertextualidad pró- 
xima con otros relatos bíblicos referentes a viudas, intentando, en términos iserianos, concretizar sus "espacios en blanco o vacíos", que nos remitirán en definitiva al sustento antropológico del imaginario analizado.

Lucas 7:11-17, reza de la siguiente forma:

(11) Y sucedió que a continuación se fue a una ciudad llamada Naím, e iban con él sus discípulos y una gran muchedumbre. (12) Cuando se acercaba a la puerta de la ciudad, sacaban a enterrar a un muerto, hijo único de su madre, que era viuda, a la que acompañaba mucha gente de la ciudad. (13) Al verla el Señor, tuvo compasión de ella, y le dijo: «No llores.» (14) Y, acercándose, tocó el féretro. Los que lo llevaban se pararon, y él dijo: «Joven, a ti te digo: Levántate.» (15) El muerto se incorporó y se puso a hablar, y él se lo dio a su madre. (16) El temor se apoderó de todos, y glorificaban a Dios, diciendo: «Un gran profeta se ha levantado entre nosotros», $y$ «Dios ha visitado a su pueblo». (17) Y lo que se decía de él, se propagó por toda Judea y por toda la región circunvecina.

$\mathrm{Al}$ analizar el texto, llama la atención la intertextualidad próxima del mismo, la que podemos sistematizar de la siguiente forma:

- En el evangelio de Lucas: Lc 2, 36-38; Lc 4, 25-26; Lc 18, 1-5; Lc 20, 4647; Lc 21, 1-4.

- En el evangelio de Marcos: Mc 12, 41-44

- En el Antiguo Testamento: 1 Reyes 17, 8-24; 2 Reyes, 4

Así pues, en mayor o menor medida, los relatos bíblicos mencionados presentan elementos que nos ayudan a configurar el arquetipo marginal analizado, y junto con ello, nos iluminan en relación a los mitemas presentes en el mismo, los cuáles clasificaremos de la siguiente forma: la presencia de una mujer viuda y pobre, la figura del hijo varón, la queja y la ofrenda de la viuda. El texto de Lucas 7:11-17, será analizado en atención a ellos.

\subsubsection{La mujer viuda y pobre}

Tanto en la literatura universal como en los citados relatos bíblicos, la mujer viuda y pobre constituye un mitema, que en proceso de constante ficcionalización, deviene en categoría antropológica. En este sentido, debemos considerar que, desde la antigüedad, se elabora ficción sobre una condición humana silenciada, que carece incluso del estatuto jurídico de persona; más el autor que ha constatado esa realidad, primero la ficcionaliza, la cultura se encarga de transformarla en imaginario y en el constante cruce de fronteras entre realidad y universos narrados, trasforma a esta 
anónima viuda pobre en sujeto político. El evangelio de Lucas, resulta ilustrativo al respecto.

En tal sentido, los antecedentes sobre el estatus sociocultural, jurídico y religioso de la mujer y la viuda bíblica en tiempos de Jesús, nos otorgan una base contextual para comprender su condición doblemente marginada: no sólo era mujer, sino que además viuda.

Desde una perspectiva sociocultural, en los códigos de Israel, como en los del antiguo Oriente Medio, la condición de la mujer era la de una menor de edad: carecía del estatus jurídico de persona, siendo considerada un instrumento u objeto de derecho. Respecto a su rol en la vida social, Jeremias (1980: 371), destaca que, en Oriente, no participa la mujer en la vida pública; lo cual es también válido respecto al judaísmo del tiempo de Jesús. Desde una perspectiva jurídica, la patria potestas era extraordinariamente grande, la mujer era propiedad de su marido y miraba a éste como su amo, actitud que se encuentra todavía en tiempo del Nuevo Testamento (Conell \& Dowley, 1983).

Tales condiciones descritas se reflejaban igualmente en las prescripciones de la legislación religiosa de la época, especialmente en su posición ante la Torá, pues la mujer tampoco era igual al hombre; estaba sometida a todas las prohibiciones de la Torá y a todo el rigor de la legislación civil y penal, comprendida la pena de muerte, al respecto Jeremias, destaca:

En conjunto, la situación de la mujer en la legislación religiosa está muy bien reflejada en una fórmula que se repite sin cesar: «Mujeres, esclavos (paganos) y niños (menores)»; la mujer, igual que el esclavo no judío y el niño menor, tiene sobre ella a un hombre como dueño, lo cual limita también su libertad en el servicio divino (Jeremias, 1980: 385).

En orden a lo anterior, no es extraño que la condición de viudez, viniera a profundizar el estatus marginal de la mujer judio palestinense del siglo I, sometida a su pasado horizonte cultural desarrollado en el Antiguo Testamento. Así, es necesario reconocer que la actitud que se tenía en el siglo I frente a la viuda, y en general la visión sobre el sexo femenino neotestamentario sigue sujeta a los códigos de Israel y a sus leyes dadas principalmente en Levítico y Deuteronomio. La mujer era considerada ámãnãh (viuda) cuando su marido había fallecido y ella no tenía ningún hijo adulto ni yerno que pudiera encargarse de mantenerla, ni cuñado que se uniera a ella según la costumbre del levirato de la que daba cuenta Dt 25:5-6.

De lo anterior, sólo cabe concluir la precaria situación de la viuda, quizás sin un equivalente social y jurídico exacto en la actualidad, silenciada y deshumanizada, nos ayuda a comprender la importancia del mitema del 
hijo varón presente en el imaginario marginal, el cual analizaremos a continuación.

\subsubsection{El hijo varón}

Desde textos antiguos, como los citados "Ayax", "La Iliada" y "La odisea", pasando por el texto de 1 Reyes 17: 8-24 y Lucas 7: 11-17, la imagen del hijo varón, es central en el desarrollo de ficciones en torno a la mujer viuda. Ya sea por argumentos arraigados en el sustento material que el hijo varón representa o en conjeturas de tipo psicológico, es innegable la importancia del hijo único varón en la configuración del imaginario y las evidentes y trágicas consecuencias jurídico-sociales que la muerte de éste representa para la viuda.

En este sentido, en la antigüedad, la relevancia del hijo varón, como único sustento material en la vida de una madre viuda, nos permite constatar, que el destino de las mujeres viudas era esperar vivir con sus hijos varones, cuyo deber primario, era cuidar a su madre y el fracaso en el cuidado de la propia madre viuda era la indicación más segura de un quiebre moral completo (Gallego, 2003) toda vez que el hijo representaba la figura masculina a cuyo yugo se subordinaría la mujer tras la muerte del esposo.

Así es como en los códigos de Israel del siglo I, la influencia femenina, quedaba vinculada a su función maternal, pues el tener niños, especialmente varones, era muy importante para la mujer y la carencia de hijos era considerada como una gran desgracia, incluso como un castigo divino (Crochetti, 2004). La mujer, al ser madre de un hijo, era jurídico-socialmente considerada, dentro de las limitaciones ya señaladas.

En este sentido, el trágico cuadro escenificado por Lucas en Naím, ciudad ubicada en el camino que partiendo del lago de Genesaret y pasando al pie del Tabor, conducía a Samaria (Stöger, 1975), nos lleva a comprender la desoladora condición de la viuda que encabeza el cortejo fúnebre. Al respecto, y siguiendo a García-Viana (1989), es relevante hacer hincapié, que en una sociedad en la que la seguridad de la mujer dependía de los hombres de su familia, esta viuda, que ha perdido a su hijo, se encuentra completamente indefensa. No obstante, y en forma paradojal, pertenece a los pobres y pequeños que Jesús había declarado dichosos ( $\operatorname{Lc} 6$, 20-21). Bovon (2010) agrega por su parte, una referencia de tipo psicológica: el psicoanálisis nos ha hablado de la importancia fundamental de la relación madre-hijo y los efectos patológicos que puede tener. Es evidente, pues la situación de ruptura de la lógica natural que esta madre experimenta: la vida nos habitúa a que sean los hijos quienes den sepultura a los padres; la dureza del dolor que implica sepultar a un hijo es incomprensible 
respecto a otro dolor humano. Pero de suma relevancia, también es comprender la situación en el marco de entonces: la relación madre e hijo, la más estrecha de todas, estaba además orientada hacia el porvenir, ya que el hijo era la única riqueza de una viuda pobre y su seguro para los últimos días de su vida.

Con todo, al parecer la realidad de fondo en la que piensa Lucas, no solamente hace referencia intertextual a la situación particular de los libros de los Reyes (1 Re 17; 2 Re 4), sino también, más en general, en la tragedia de perder a un hijo único, atestiguada por la tradición sapiencial ${ }^{2}$. Así pues, en medio de una estructura y orden social en donde la mujer se encontraba en un estatus inferior y de constante dependencia de las figuras masculinas, para aquella cuyo marido ha muerto prematuramente, el hijo facilitaba su vida como mujer y como madre. En él, encontraba protección legal, sustento económico, y consuelo en el plano emocional. De esta forma, se puede entender que es tal la magnitud de la desgracia de la viuda de Naím, que Jesús al verla, se sintió lleno de compasión hacia ella y es él mismo quien en este caso predica y trae la misericordia de Dios, tocando el féretro y llamando al joven difunto como si aún viviera. Su llamada infunde vida (Stöger, 1975), el joven se incorpora y Jesús lo entrega a su madre.

\subsubsection{La queja de la viuda}

El contexto socio-jurídico de la viuda pobre, ya analizado, nos ayuda a comprender la dimensión de silencio que reafirma la marginalidad del imaginario propuesto. Su silencio contextual, viene dado desde una dimensión incluso etimológica. El relato analizado, de acuerdo a Lacueva (1984:255), conceptualiza la condición descrita utilizando la expresión griega $\chi \dot{\eta} \varrho \alpha$ ("chèra"), de la misma forma en que se encuentra la expresión en Lc 21, 1-4, y que de acuerdo a Thurston (1989:10), proviene de la raíz indoeuropea ghè, que significa "abandonado" o "dejar vacío".

Así, parece evidente, que según el contexto jurídico-social de la palabra referida, ésta alude al estado más pasivo y necesitado de la mujer en la sociedad antigua, representado por el de aquella mujer que se quedó sin un cónyuge, constituyéndose en una "viuda", o una "persona sin una fuente de apoyo", resaltándose el aspecto económico-material, presente en tal caracterización, casi uniformemente en el mundo antiguo (Thurston, 1989: 10), pero que sin embargo, ficcionaliza en el texto analizado, una

2 Señala Bovon (2010), que el duelo por el hijo único, es además en el Antiguo Testamento un concepto fijo para expresar la profundidad del dolor (Am 9, 10; Jr 6,26; Zach 12,10). No obstante lo anterior en 1 Re 17, 15-17, la viuda al parecer, tiene otros hijos. Al contrario, el hijo de la sunamita de 2 Re 4, 8-37, sí es único. 
situación mucho más cruenta que la simple dependencia económica o material y que resalta en la pragmática de su contexto social, pues podemos entender su condición como parte de aquellos que transitan por el reino de la muerte, sin nombre, incapaz de hablar o de ser nombrada por otros, tal y como da cuenta la raigambre griega del concepto, y que se reafirma en su expresión hebrea: almãnăh, de la raiz alem, que significa "incapaz de hablar" (Thurston, 1980: 9).

De lo expuesto, resalta la dimensión paradojal del imaginario estudiado. Es así como en las viudas lucanas, constituye un mitema la figura de esta mujer pobre, que no obstante su silenciada condición social, no teme alzar la voz representando las injusticias de las estructuras sociopolíticas que le oprimen. Decidora es al respecto la parábola de la viuda y el juez injusto, de Lc 18, 1-5, centrada en un juez, acaso desalmado, que no se molesta en hacer justicia a una pobre viuda. Pero ella le urgía resolviese su asunto volviendo sobre él con insistencia. El juez, molesto ante la situación se decide a hacerle justicia, para evitar que le siga importunando.

El texto es decidor, en él evidenciamos el mitema que constataremos más adelante al analizar el cuento "El pago" en la literatura de Baldomero Lillo, y que en cierta forma ya figura presente en el texto de 1 Reyes, 17: 8-24: "la queja", pero no cualquiera, sino aquella proveniente del mundo femenino y particularmente de una mujer viuda y pobre. Es profundamente llamativo que en este texto la que urja al juez a hacer justicia, sea una viuda; se repite el mismo esquema de privilegiar a la figura de ésta pobre entre los pobres, pero a diferencia de otros textos lucanos, como el de Lc 2: 36-38 y la figura de la profetiza Ana, ya no avocada a labores piadosas y de culto, como el ideal de viuda judía y cristiana (Bovon, 2010) sino alzando la voz en la exigencia de justicia y en una clara y paradojal actitud de emancipación, completamente novedosa en cuanto al rol de la mujer viuda prefigurada en la tradición judeo-palestinense del siglo I.

\subsubsection{La ofrenda de la viuda}

Más allá de toda caracterización con predominio de rasgos negativos que socioculturalmente han marcado su condición, cabe resaltar la existencia de una dimensión soteriológica, presente en los actos de la mujer viuda pobre, y que podemos encontrar en textos bíblicos y sagrados de otras culturas, como el citado relato budista recopilado por Haas.

En este sentido, destaca Fitzmyer (2006) que la idea de que los pequeños sacrificios realizados por los pobres son más agradables a los dioses que las extraordinarias contribuciones de los ricos, es un tema común en la literatura griega por lo menos desde el siglo VI a.C. 
Así, evidenciamos en las viudas lucanas, esta dimensión -que a veces silenciosa en otras alzando la voz- lleva envuelta una dimensión salvífica, que a partir de sus padecimientos cotidianos, humaniza las acciones de su pueblo.

Ahora bien, de la viuda de Naím, no sabemos a ciencia cierta su condición de pobreza, no obstante ello, es el contexto descrito en la primera parte del relato, el que nos enmarca en un escenario particular, dando cuenta de su condición marginal. Así pues, se indica que al acercarse a las puertas de la ciudad, sacaban a enterrar al muerto. Se otorga una referencia respecto a su situación, pues éste era apartado de la ciudad para enterrarle; lo anterior, nos lleva a preguntarnos: itodos eran apartados de la ciudad para ser enterrados o tal antecedente da luces sobre el grupo social de pertenencia?

Al respecto, señala Estévez (2004: 209):

Fuera de las murallas de la ciudad, a lo largo de los caminos y a las puertas de las casas de los ricos y del Templo vivía una población marginada. Las calles de las ciudades y sus sendas hacia fuera demuestran la distribución socioeconómica de la población y el tipo de intercambios que se producen.

Cabe recordar en concordancia con Estévez, que el lugar de los endemoniados, los leprosos y toda clase de excluidos era el desierto o los lugares retirados de la ciudad. La muerte biológica del hijo de la viuda y su salida de las puertas de la ciudad, parece enmarcar el cuadro de entrada a un reino de la muerte que circundaba las ciudades y en donde habitaban los excluidos de la sociedad, evidenciando la marginalidad de la viuda descrita y la dimensión salvífica presente en su condición. Lo anterior, se manifiesta al sentir Jesús una sincera compasión por el dolor de esta madre viuda, dejando entrever la acción de carácter soteriológica, que es acogida con estupor por la multitud al constatar el valor sobrenatural envuelto en una situación tan humana como lo es el duelo de una madre.

De esta forma, Lucas ficcionaliza en torno al elemento salvífico de la entrega de la viuda que, en última instancia, corresponde a una entrega de vida, pues aquella que nada tiene, ¿qué más puede entregar si no es su propia vida?, en lo más mísero y cotidiano de su existencia. Así, el mitema se reitera en Lc 2: 36-38 respecto a la profetiza Ana y su entrega de vida en la cotidianeidad de las plegarias que entona en el templo y con mucha mayor fuerza, en Lc 21, 1-4, sobre la ofrenda de la viuda, quien radicalizando la narración marcana, acentúa en su narración el contraste entre la viuda pobre y los otros, y como resalta Fitzmyer (2006), con el objetivo de que Lucas, pueda demostrar en el episodio de los óbolos, que a Jesús tampoco le gusta lo que acaba de ver, y lejos de alabar la situación, lamenta la 
tragedia de la viuda, condenando el sistema de valores que ha motivado su conducta, pues los jefes religiosos la han enseñado y animado a hacer una ofrenda como la descrita, que representa todo cuanto necesita para vivir.

Así pues, y en definitiva, vemos como el arquetipo marginal de la mujer viuda pobre se encuentra enmarcado en un "esquema teológico paradojal" (Carbullanca, 2014: 146), que tal como en las bienaventuranzas, nos presenta a la viuda pobre lucana, como beneficiaria del eschaton (Carbullanca, 2014: 146), permitiendonos además, constatar en el imaginario, aquella "trasmutación total de los valores" de la cual nos habla Jeremias (1974: 248).

Veamos a continuación, la recepción de dicho modelo en una obra de la literatura universal: Los cuentos “El pago” y "El Chiflón del Diablo", ambos del escritor chileno Baldomero Lillo.

\section{RECEPCIÓN ESTÉTICA DE LA VIUDA POBRE COMO PARADIGMA DE SIERVO SUFRIENTE EN LA OBRA DE BALDOMERO LILLO}

La teoría del acto de leer y su consiguiente efecto estético, nos permite pensar y postular la recepción de la Biblia de una forma diversa: el texto bíblico en el proceso de reinterpretación de la cultura Nogueira, 2012: 16). En este apartado, se establecerá la recepción del imaginario propuesto, en los cuentos mineros de Baldomero Lillo —específicamente"El Chiflón del diablo" y "El pago" (2008) - escritor chileno, considerado un maestro del realismo social y quien publicara su obra en los albores del siglo XX, profundamente inspirado por las experiencias acumuladas en las minas de carbón de Lota, mismas experiencias que le permitieron escribir una de sus obras más famosas "Sub terra", en donde retrata la desoladora vida de los mineros del carbón.

En este sentido, en el desarrollo de procesos ficcionales de concretización, se puede sostener que los mentados cuentos de Lillo, participan de la recepción de los mitemas analizados en el apartado anterior. A continuación, estudiaremos la forma en que opera la recepción estética del imaginario en estudio, resaltando la dimensión soteriológica presente en el actuar de la viuda pobre descrita por Lillo en sus cuentos mineros.

\subsection{Recepción del mitema de la mujer viuda y pobre}

Tanto en los cuentos de Lillo (2008) como en la literatura bíblica mencionada, la mujer viuda pobre constituye un mitema. Las viudas que el autor nos presenta en los relatos en estudio, son ilustrativas en torno a la condición de pobreza y marginación caracterísitca del imaginario propuesto. Así, en "El Chiflón del Diablo”, María de los Ángeles, madre de 
Cabeza de Cobre, es descrita como una viuda, alta, delgada, de cabellos blancos, rostro pálido y expresión resignada, mientras que en "El pago", se caracteriza a una viuda anónima, joven, alta, bien formada, bello rostro, rojos labios y blancos dientes, madre de José Ramos niño portero de doce años, tan paliducho y raquítico que no parecía de más de ocho.

En un mismo sentido, para comprender el triste devenir de estas viudas, debemos centrarnos en Lota, la pequeña localidad minera situada en la Provincia de Concepción, Región del Biobío, Chile, a fines del siglo XIX, en donde la pujanza económica de la empresa carbonífera de los Cousiño contrasta con la miseria y marginación de los mineros y sus familias. Así pues, el imaginario minero, del carbón en particular, se ha transmitido culturalmente a través de ideas arquetípicas que han llegado a nosotros por medio de la literatura y el cine. Concha (2008), estima que se trata de un imaginario a menudo trasplantado de uno a otro en un avatar de géneros artísticos y de cuya transmisión evidentemente no ha escapado la obra de Lillo, en intertextualidad directa, por ejemplo, con la obra "Germinal" de Émile Zola ${ }^{3}$.

\subsection{Recepción del mitema del hijo varón}

El mitema del hijo varón, particularmente el de su muerte, presenta en "El Chiflón del Diablo", significativas similitudes a cómo se nos narra el relato de Lucas 7:11-17, a excepción obviamente de la resurrección del joven muerto. En el caso del "El pago", el hijo de la viuda no ha muerto, sin embargo, tal indeterminación, no parece demasiado compleja de concretizar, pues inmerso en el dantesco contexto que rodea a la mina, el pequeño José Ramos, se encuentra condenado a la reiteración del escenario de muerte que segó la vida de "Cabeza de cobre", parafraseando el mismo pensamiento de éste último: "Fatalista, como todos sus camaradas, creía que era inútil tratar de sustraerse al destino que cada cual tenía de antemano designado".

Así las cosas, parece relevante destacar la importancia de la indeterminación relativa a la resurrección del hijo, resaltando el sentido material y político de ésta, pues "el sentido original de la fe en la resurrección (...) posee un aspecto esencial relacionado al hacer justicia a las víctimas" (Carbullanca, 2013: 411), dimensión que Lillo silencia en sus relatos.

3 Al respecto, véase Brown: "A Chilean Germinal: Zola and Baldomero Lillo"; Sedwick: "Baldomero Lillo y Emile Zola"; Hasbún: "El realismo de Baldomero Lillo"; Bocaz: "Sub terra de Baldomero Lillo y la gestación de una conciencia alternativa"; Concha: "Lillo y los condenados de la tierra"; Fraser: "Baldomero Lillo's underground literary modernism"; Marks, en su prólogo a "Obra Reunida" Ril editores, entre otros. 


\subsection{Recepción de los mitemas de la queja y la ofrenda de la viuda}

Es preciso analizar en conjunto estos mitemas, pues llama la atención que en los relatos estudiados, se evidencia esta doble dimensión presente en el imaginario y particularmente marcada en los cuentos de Lillo; tenemos por un lado a María de Los Ángeles y su ofrenda sufriente y silenciosa, relatada en "El Chiflón del diablo" la que contrasta con la queja activa y directa de la viuda anónima de "El pago". En un mismo sentido, observamos también esta dualidad en los textos bíblicos analizados: el absoluto silencio de la viuda de Naím, quien es objeto de la compasión y acción de Jesús o el silencio en la viuda que entrega su ofrenda en Marcos 12 y Lucas 21, en oposición por ejemplo, al rol activo de la viuda de Lucas 18: 1-5, quien exige al juez que le haga justicia o la misma viuda de Sarepta, que enmarcada en una tradición diversa, presenta el elemento de la queja, al reprochar al profeta Elías, la muerte de su hijo.

De esta forma, la viuda de "El pago", muestra esa intrínseca capacidad humana de indignarse, presentando materialmente el descontento hacia el sistema que la oprime y por primera vez, alzando su voz en contra de aquellos que explotan y luego roban el trabajo de su hijo, al alero del sistema de producción; marcando además, un punto de inflexión con el resto de la narración y la constante visión del obrero vencido por el infortunio, que desaparece para dar paso por unos instantes, a la imagen de esta mujer viuda, que indignada vocifera, a la vez que en ese vociferar, se constituye como sujeto político con la conciencia de que su indignación, puede establecer la pequeña base de grandes cambios estructurales.

Finalmente, María de Los Ángeles, en "El Chiflón del diablo", hace patente la dimensión expiatoria presente en los actos de la mujer viuda. En este sentido, concordamos con Spicer-Escalante, al estimar que el proceso de deshumanización que detalladamente nos relata Lillo en su obra, halla su contrapartida en el proceso humanizador al que recurre en términos de los protagonistas; el cuadro pseudohagiográfico de caracterización de María de los Ángeles, la convierte a juicio del autor, no sólo en la verdadera protagonista del cuento, sino en una especie de "matriarca nacional, Virgen obrera, sufrida y dedicada al bienestar de su pueblo" (SpicerEscalante, 2001:78), víctima de las iniquidades del sistema capitalista, que en la situación más abyecta e ignominiosa, como es el suicidio, consigue ahogar su último grito de sufrimiento vicario, en las fauces del mismo sistema que los devora, como víctima expiatoria por el sufrimiento de su pueblo. En este sentido, su propia muerte constituye ofrenda y queja a un mismo tiempo. 
3.4. Conclusiones en torno a la recepción del paradigma en la obra de Baldomero Lillo

Así pues, constatados tales mitemas, cabe concluir que al igual que la viuda bíblica, las viudas de Lillo, figuran en definitiva, junto con los huérfanos, entre los más pobres de la sociedad o los más pobres entre los pobres, estando inmersas en una atmosfera construida sobre el mito de un reinado de muerte, el de los llamados "condenados de la tierra", en que el trabajo del minero está hecho por prisioneros sujetos al orden material y social que los esclaviza (Concha, 2008) y en el cual las mujeres están silenciosamente introducidas, con sus sufrimientos de madres, hijas o viudas.

No obstante lo anterior, en forma paradojal el proceso de deshumanización que detalladamente nos relata Lillo en su obra, y que de acuerdo a Spicer-Escalante (2001) halla su contrapartida en el proceso humanizador al que recurre en términos de los protagonistas de sus cuentos, se destaca particularmente, como hemos señalado, en la figura de la viuda, cuyas meditaciones inarticuladas, en palabras del autor le permiten a Lillo pensar "en voz alta" (Spicer- Escalante, 2001: 78), y expresar el fundamento básico de un ideario contradiscursivo, que si bien no se hace explícito, es pragmáticamente evidente:

El discurso organizador liberal basado en el sistema capitalista que se utilizó para fundar la nación chilena moderna también produce la desigualdad innata que divide y destroza esa misma nación (Spicer-Escalante, 2001: 78).

Ahora bien, si nos situamos contextualmente, podemos ver que la obra de Lillo favorece la entrada en escena de un nuevo grupo o categoría de sujetos marginales portador de un discurso divergente respecto de los grupos dominantes. En concordancia con Bocaz (2005), estimamos que este nuevo mediador cultural, proveniente en su mayoría de las capas bajas o medias emergentes, permite descubrir en la obra de Lillo los signos anunciadores de una conciencia alternativa cuya consolidación y desarrollo constituirá el credo fundamental de sus alianzas ideológicas con otros actores sociales a lo largo del siglo XX' Tal antecedente, nos lleva a establecer la recepción en relación a la emergencia en los relatos de los primeros cristianos, de grupos de marginales, que al igual que los personajes de la obra de Lillo, aspiran materializarse en la subsecuente consecución de derechos civiles y políticos que les permita tener una participación activa dentro del quehacer sociopolítico de sus respectivos contextos históricos.

En definitiva, las imágenes presentadas por el texto de Lucas 7: 11-17 y los cuentos "El chiflón del diablo" y "El pago" de Baldomero Lillo, se enriquecen mutuamente. Así, podemos precisar que el evangelio de Lucas, 
que nos presenta a un Jesús humanizado a través de su atención a los pobres y que elabora una cristología unida a la relación viva con Cristo (Bovon, 2010), expresa que a través de las relaciones personales es como los hombres y mujeres participan en la instauración del reino de Dios en la historia y a su vez, se constituyen en sujetos políticos con fuerza de acción y posibilidad de cambio, otorgándonos un elemento propiciador de diálogo con los cuentos de Baldomero Lillo. Así pues, el evangelio de Lucas, otorga una dimensión de salvación en la historia que ayuda a concretizar el discurso político que Lillo aparentemente silencia, pero que es evidente a través de indicadores pragmáticos. La obra de Lillo, escrita en un contexto de sufrimiento, amenazas y violencia en contra de un grupo marginal de la sociedad, constituye un poderoso cúmulo de imágenes y metáforas capaces de otorgar sentido a la dimensión de salvación presente en un personaje marginal concreto, como es la viuda pobre que a la luz del evangelio, puede, en su entrega de vida, entrar en comunión con Dios y ayudar al pueblo en la salvación de sus pecados, a través de una lucha concreta, que en la justicia y solidaridad de su entrega, constituye un aporte a la construcción del reino.

\section{OBSERVACIONES FINALES}

A partir de la reiteración del motivo literario de la viuda pobre, es posible sostener que las ficciones literarias revelan una disposición profundamente engranada de nuestro constructo, pues como bien estima Iser (1990), podemos presentarnos en el espejo de nuestras propias posibilidades y podemos lidiar con la apertura al mundo, mediante las posibilidades que derivamos y proyectamos hacia éste, desde nosotros mismos; o lo que el autor llama la espectacularización de nuestros propias contextos (Iser, 1990), configurando modelos arquetípicos o paradigmáticos que poseen una dimensión antropológica, como se probó en este caso, con la ficción de la mujer viuda pobre.

Así pues, y en definitiva, el actuar de la viuda pobre, tanto en la literatura bíblica como en la obra de Lillo, lleva implícita una dimensión soteriológica, que en sus sufrimientos cotidianos entrega salvación a su pueblo, pero además, posee tácitamente envuelta una dimensión de conciencia política, que la lleva a la praxis cotidiana de la caridad y la queja, creando en su dimensión de pobreza, una conciencia de asistencia mutua y solidaridad que se opone al ideario de producción deshumanizador del sistema económico que la oprime.

En el estudio de la recepción del modelo literario señalado y en el entendido de que a la luz de la estética de la recepción, la ficción literaria de viuda pobre constituye una categoría antropológica que nos permite 
comprender elementos fundamentales de la realidad de esta mujer, se pretende enfatizar la posibilidad de encontrar la comunión con Dios en las miserias y tribulaciones del justo que sufre. Se evidencia asimismo la recepción bíblica en un texto de la cultura, pues Lillo en sus cuentos, postula una suerte de salvación "desde el mundo de los pobres y marginados, dando cuenta del modelo propuesto, paradojal, en tanto que Dios escoge a un excluido social como protagonista de la salvación, ayudando a desenmascarar el dogma de que un pueblo de pobres puede recibir y no dar" (Sobrino, 2006: 5) pues ya en Isaías 42,6; y 49,6 se dice del Siervo que es "luz de las naciones".

\section{REFERENCIAS}

-Betancourt, M.E. (2005). La ficcionalización: dimensión antropológica de las ficciones literarias de Wolfgang Iser. Lectura crítica. Recuperado del sitio Editorial Letralia de, https://letralia.com/ed_let/15/05.htm

-Bocaz, L. (2005). Sub terra de Baldomero Lillo y la gestación de una conciencia alternativa. Estudios Filológicos, (40), 7-27.

-Bovon, F. (2010). El Evangelio según San Lucas. Salamanca: Sígueme.

-Carbullanca, C. (2013). Martirio y arrebato en la apocalíptica judía. Una propuesta de estética teológico-bíblica. Teología y Vida, (54), 411-439.

-Carbullanca, C. (2014). Los mártires olvidados. Un estudio de los imaginarios del martirio en la fuente de los dichos. Veritas, (31), 135-160.

-Concha, J. (2008). Lillo y los condenados de la tierra. En B. Lillo, Obras Completa, edición crítica (pp. 15-67). Santiago de Chile: Ediciones Universidad Alberto Hurtado.

-Conell, R. \& Dowley, T. (1983). Enciclopedia de la Biblia. Madrid: Editorial Verbo Divino, Ediciones Paulinas.

-Crochetti, S. (2004). Ser madre, ser mujer, ser humana: las mujeres en el antiguo Israel, las políticas natalistas y la legitimación religiosa. Revista La Aljaba, (9), 175-188.

-Estévez, E. (2004). Jesucristo, Hijo de David y benefactor que otorga la salud: La curación de los ciegos de Jericó (Mt 20,29-34). En S. Castro, F. Millán \& P. Rodríguez Panizio (Eds.), Umbra, Imago Veritas: Homenaje a los profesores Manuel Gesteira, Eusebio Gil y Antonio Vargas-Machuca (pp. 183-222). Madrid: Publicaciones de la Pontificia Universidad de Comillas.

-Fitzmyer, J. (2006). El Evangelio según Lucas, Volumen 4. Madrid: Ediciones Cristiandad.

-Gallardo, E. (2011). Anotaciones a la poética aristotélica. Una aproximación desde el punto de vista de la teoría literaria. Recuperado del sitio Colección Interciencias, Blog UNED sobre Teoría de la Literatura, de: http://peripoietikes.hypotheses.org/509].

-Gallego, J. (2003). El mundo rural en la Grecia antigua. Madrid: Ediciones Akal. 
-García-Viana, L. (1989). ElMensaje del Nuevo Testamento. Evangelio según San Lucas. Salamanca: Ediciones Sígueme, Editorial Verbo Divino.

-Gómez, F. (2007). Wolfgang Iser: Biografía. Recuperado del sitio MCN Biografias, de http://www.mcnbiografias.com/app-bio/do/show?key=iser-wolfgang

-Haas, H. (1922). Das Scherflein der Witwe und seine Entsprechung im Tripitaka. Leipzig: J. C. Hinrichs'sche Buchhandlung.

-Iser, W. (1987). El acto de leer. Teoría del efecto estético. Madrid: Taurus.

-Iser. W. (1990). Fictionalizing: The Anthropological Dimension of Literary Fictions. New Literary History, 21, 939-955. Recuperado de Cyber Humanitatis, traducción y notas por Vicente Bernaschina Schürmann, de http://web.uchile.cl/vignette/cyberhumanitatis/CDA/texto_sub_simple2/0,1257,PRID \%253D14079\%2526SCID\%253D14081\%2526ISID $\% 2$ 53D499,00.html

-Jeremias, J. (1974). Teología del Nuevo Testamento. Salamanca: Ediciones Sígueme.

-Jeremias, J. (1980). Jerusalem en tiempos de Jesús. Madrid: Biblioteca Bíblica Cristiandad.

-Lacueva, F. (1984). Nuevo Testamento Interlineal Griego-Español. Barcelona: Editorial Clie.

-Lillo, B. (2008). Obra Completa, edición crítica. Santiago de Chile: Ediciones Universidad Alberto Hurtado.

-Nogueira, P. (2012). Hermenêutica da Recepçã: textos bíblicos nas fronteiras da cultura e no longo tempo. Estudos de Religião, Sao Paulo, (42), 15-32.

-Sánchez, A. (2005). Tercera conferencia: La Estética de la Recepción; La estructura apelativa del texto; Ideas fundamentales de la Estética de la Recepción. De la Estética de la Recepción a una estética de la participación. En S. Vásquez, De la Estética de la Recepción a una estética de la participación (pp. 49-62). Mexico D.F.: Relecciones.

-Sobrino, J. (2006). El pueblo crucificado y la civilización de la pobreza. Recuperado de http://www.uca.edu.sv/facultad/chn/c1170/El\%20pueblo-crusificado-yla-civilizacion-de-la-pobreza-el-hacerse-cargo-de-la-realidad-de-Ellacuria.pdf

-Sófocles (2000). Tragedias, Ayax. Madrid: Biblioteca Básica Gredos.

-Spicer-Escalante, J. P. (2001). El Chiflón del Diablo de Baldomero Lillo, alegoría de la nación chilena moderna. Anales de literatura chilena, (2), 65-80.

-Stöger, A. (1975). El Nuevo Testamento y su mensaje. El Evangelio según san Lucas. Barcelona: Herder.

-Thurston, B. (1989). The widows, A women's Ministry in the early church. Minneapolis: Fortress Press.

Sumario: Introducción; 1. La Estética de la Recepción y la ficción literaria de la viuda pobre como categoría antropológica; 1.1. La estructura del texto y el proceso de recepción; 1.2. La Ficcionalización y dimensión antropológica de las ficciones literarias; 1.3. La ficción literaria de la viuda pobre; 2 . La viuda pobre como arquetipo marginal en el evangelio de Lucas; 2.1. Análisis del texto de Lucas 7:1117 "Jesús resucita al hijo de la viuda de Naín"; 2.1.1. La mujer viuda y pobre; 
2.1.2. El hijo varón; 2.1.3. La queja de la viuda; 2.1.4. La ofrenda de la viuda; 3. Recepción estética de la viuda pobre como paradigma de siervo sufriente en la obra de Baldomero Lillo; 3.1. Recepción del mitema de la mujer viuda y pobre; 3.2. Recepción del mitema del hijo varón; 3.3. Recepción de los mitemas de la queja y la ofrenda de la viuda; 3.4. Conclusiones en torno a la recepción del paradigma en la obra de Baldomero Lillo; 4. Observaciones finales; Referencias. 